eschewed, the hospital sired (or at least was godfather to) a Special Hospital Research Unit.

In the big outside world, 'forensic psychiatry' became a familiar and acceptable description of a subdiscipline; flourishing academic departments came into being in Edinburgh and Birmingham, as well as at Denmark Hill. Reports and publications proliferated, and Regions were encouraged to set up special units and appoint consultants to cater for forensic psychiatric needs. Now a sister Special Hospital has taken root and flourishes on Merseyside.

The essentials of the job at Broadmoor, however, have not changed, though in the performance of it one increasingly had the support and advice of colleagues of many disciplines. These essentials were and are the treatment and assessment of those who have been statutorily labelled as 'dangerous', the protection of the public, and the protection of the rights (including the right to treatment) of patients. The work is carried out in the increasingly lurid, sometimes blinding, glare of publicity; one must react, and not over-react, to public interest and public pressures. Some twenty years ago, an official asked me if I did not feel isolated; I had to reply that I felt as isolated as one standing in the middle of Piccadilly Circus, which my office sometimes resembled. To my great enjoyment, visitors come to the Hospital in single spies and in battalions; from California, from Cathay (literally!), and nearly everywhere in between-politicians and professors, dons and do-gooders, the critical and the constructive. Many came to preach-but some, with enough humility, came to learn. Above all, there were the patients, all the time; many with tragic histories, some tragi-comic or bordering on the farcical, and some were deeply moving. It was they and their relatives who made it all worthwhile. Despite the pressures, public and political, one was never moved to apply for 'conversion and transfer'. When things were going well, there were no greater rewards or fun to be had in psychiatry; when things were going ill, one could not possibly quit.

So I lived out a quarter of a century as the last Medical Superintendent of Broadmoor, and have now, rational and tranquil, handed over to a Medical Director.

ACKNOWLEDGEMENT

Much of the historical paragraphs relating to development before 1900 is based on Professor Nigel Walker's Crime and Insanity in England, and I am indebted to him.

\title{
Clinical Hypnosis for Psychiatrists in Training
}

\author{
W. A. Barker, Lecturer and M. Place, Senior Registrar, Department of Psychiatry, Newcastle upon Tyne
}

Interest in the application of hypnosis to clinical psychiatry has increased recently in this country. In the 1950s it had been recommended (Subcommittee of the Psychological Medicine Group, 1955) that experience of the techniques of hypnosis should be available to all medical undergraduates and to postgraduate trainees in certain specialties, including psychiatry. Such a training would lead to an awareness of the practical use and limitations of hypnosis, and would also allow an informed and rational decision to be made about its employment in the practice of medicine. Despite this recommendation, a review twenty years later (Scott, 1978) showed that teaching of hypnosis was a rare feature of medical training.

Most of the teaching about hypnosis and its techniques is carried out on courses organized by the British Society of Medical and Dental Hypnosis, and the recently formed British Society of Experimental and Clinical Hypnosis. The techniques taught are varied and are applicable to many areas of medicine and dentistry, but it may be prudent to ask whether these courses meet the specific needs of psychiatrists in training. In Newcastle four courses were organized in the Department of Psychiatry which were quite separate from those run by the national societies. Teaching was done by psychiatrists who use hypnosis regularly as part of their clinical practice, and the courses were open to all psychiatric trainees in the area. The impetus for establishing the workshop was from trainees who, knowing of the interest in hypnosis of some local psychiatrists, sought out instruction in its techniques.

The course is designed to focus on factors that seem of particular relevance to psychiatric work. It is assumed that trainees are attending the course to gain knowledge and are not necessarily planning to use the techniques clinically. Emphasis is laid upon the fact that hypnosis in psychiatry is not an all-embracing treatment, but more an additional therapy to be used as and when appropriate alongside established treatments. The sessions are primarily experiential because this helps towards a clearer understanding of the phenomena of hypnosis and highlights the facets of the process that may be of potential therapeutic benefit. The whole programme takes approximately six hours, but each group dictates the actual intensity and depth of the course. The format is flexible and tailored to accommodate the work circumstances of the participants. A manual is distributed beforehand containing descriptions of induction procedures and treatment strategies which are to be illustrated.

\section{Course structure}

The programme can be divided into five parts. The first segment consists of an introduction to the subject of 
hypnosis and its history. Particular emphasis is placed on areas of research interest and popular misconceptions about the hypnotic process are discussed. There is a constant effort to demystify the procedure and bring it to the level of a practical therapy. The second segment of the programme is a demonstration of an hypnotic induction, using a trainee as subject. The assessment procedure, which was devised in Newcastle and is used clinically in this area to quantify hypnotic facility, is presented and discussed. The group then divides into pairs and each trainee explores the assessment procedure with his partner as subject. Each participant experiences the hypnotized state as well as inducing it in his colleague. The group members then summarize and discuss the hypnotic potential that their partners have shown.

The third segment concentrates on the use of hypnotic facility to gain relief from anxiety symptoms. Specific anxiety control techniques are discussed, and the treatment strategies which have been found to be most effective in clinical practice are explained to and examined by the group. The use of hypnosis in relaxation and behavioural programmes is also explored to assess its role in a treatment programme. The demonstration of the technique begins with a different induction procedure, and throughout the programme a variety of induction procedures are demonstrated so that the trainee can experiment and discover the one with which he feels most comfortable.

The techniques of self-hypnosis are dealt with in the fourth segment. A discussion and demonstration are followed by practice in pairs, and trainees are encouraged to continue practising their own self-hypnosis sequence in order to understand some of the practical problems experienced by patients who use this technique. It is appropriate to describe other methods of maintaining improvement, such as prerecorded tapes, which are used when the patient's facility is not great enough to allow him to use self-hypnosis successfully. Emphasis is placed on self-hypnosis, however, because it is the philosophy of those practising within the Department of Psychiatry that the reliance of patients upon the hypnotherapist should be kept to a minimum. It is thus the routine practice of the clinic to teach self-hypnosis early in the course of treatment to facilitate this expectation.

The final segment is concerned with age regression phenomena. The use of age regression clinically is not common, but may be of use both diagnostically and as a therapeutic strategy. It is a technique which requires sensitive and skilled application, and must be used in conjunction with the therapist's general psychiatric, and particularly psychotherapeutic, skills. In practising these techniques the trainees are regressed to an emotionally neutral event, such as a holiday, and asked to describe the event with as much detail as possible. The process is then repeated under hypnosis and afterwards the trainees are asked to compare the vividness of the memories. It is stressed that regression should only be used in subjects who have been demonstrated to have the ability to have amnesia for the period under hypnosis. In this way it is then possible to prevent events that had been repressed because of their distressing quality from being recalled after the session. The patient is thus protected from emotionally damaging memories until their exact relevance to the problem is understood. It is important not to use hypnosis to uncover repressed material in any way that may be psychologically threatening to the patient. Preventing recall in full consciousness allows the therapist to expand his understanding of the case and guide the patient along a psychotherapeutic path to an awareness of his underlying problems.

Having given the trainees a broad experience of the hypnotic state and some insight into its clinical applications in psychiatry, those who wish to go on to use hypnosis with patients are then invited to attend the pre-existing Clinical Hypnosis Group. This meets twice monthly, and provides mutual supervision for the members. The group accepts referrals for hypnotherapy from other psychiatrists in the area and allocates them so that the group's members are always increasing their experience and improving their individual skills. Cases can be discussed and treatment strategies explored, but no routine methods are offered. The emphasis is placed upon the therapist establishing an approach with which he feels comfortable and designing strategies which take into account not only the clinical problem, but also the patient's hypnotic strengths.

Twenty trainees have so far completed the experiential course, and fourteen of these have used hypnosis clinically, under supervision. Seven regularly attend the Clinical Hypnosis Group, which receives two or three new referrals each week. The group contains two psychologists who have brought a clear understanding of behavioural theory to the core of knowledge that the group draws upon. There is little doubt that the broader the input to such a support group, the greater the variety and effectiveness of the treatment strategies that are developed.

For the past two years a similar experiential course has formed part of this University's clinical psychology training programme, and this has generated a similar high degree of interest among the participants. It seems there is no lack of interest in the phenomena of hypnosis, but to date clinical training and supervision has been sadly rare. This programme goes some way to meet these needs.

ACKNOWLEDGEMENT

We wish to thank our colleagues in the Clinical Hypnosis Group, particularly Drs H. Daudjee and I. McKeith, for their help both in the preparation of this paper and in the effective running of the group.

\section{REFERENCES}

ScoTr, D. L. (1978) University training in medical and dental hypnosis. Proceedings of the British Society of Medical and Dental Hypnosis, 4, 13-30.

Subcommittee of the Psychological Medicine Group of the Brtrish Medical Association (1955) Medical use of hypnotism. British Medical Journal 1, Supp. Appendix X, 190-3. 